\title{
Effect of different cooking procedures on cholesterol and fat contents of selected meat products
}

\author{
Nene Meltem KEKLIK ${ }^{1 *}$, Hüseyin BOZKURT², Ali Rıza TEKİN ${ }^{2}$
}

\begin{abstract}
Meat products are important sources of dietary cholesterol and saturated fat. The serum cholesterol level, which is considered a risk factor for cardiovascular disease, reportedly increases with higher intake of saturated fats and cholesterol. In this study, the effect of different cooking procedures on the cholesterol, fat, and moisture contents on wet and dry bases of selected meat products was investigated. After frying the cholesterol content of lamb $(p<0.05)$, tail fat $(p>0.05)$, and beef fried with or without olive oil $(p<0.05)$ increased. However, sucuks (Turkish dry-fermented sausages) fried with or without olive oil exhibited lower $(\mathrm{p}<0.05)$ cholesterol content compared to the initial values. After barbequing the cholesterol content of lamb kebab $(\mathrm{p}>0.05)$ and hot spicy lamb kebab $(p>0.05)$ decreased, while the cholesterol content of liver kebab $(p<0.05)$ increased. The fat content of lamb $(\mathrm{p}<0.05)$ and beef fried with $(\mathrm{p}<0.05)$ or without olive oil $(\mathrm{p}>0.05)$ increased, whereas the fat content of tail fat $(\mathrm{p}<0.05)$ and sucuks fried with or without olive oil ( $p>0.05)$ decreased. The fat content of kebabs did not change significantly $(p>0.05)$ after barbequing. Regardless of the meat product or cooking procedure, the cholesterol and fat contents on dry basis exhibited a significant decrease $(\mathrm{p}<0.05)$ after cooking.
\end{abstract}

Keywords: cholesterol; fat; meat product; cooking procedure; frying.

Practical Application: Currently, there is limited information available on the effect of different cooking procedures, especially barbequing as shish kebab, on the cholesterol and fat levels of meat products. The results of this study are expected to be a reference for dietary fat and cholesterol intake with the consumption of cooked meat products.

\section{Introduction}

Many studies have reported the correlation between a high blood cholesterol level and a high risk of the development of atherosclerotic heart disease (Piironen et al., 2002; Johnston et al., 2017). It has been reported that serum cholesterol level, which is a risk factor for coronary heart disease, increases with higher intake of saturated fats and cholesterol (Willett, 1994; Wagemakers et al., 2009). Current dietary cholesterol recommendations are in the range of 200-300 mg/day (Kanter et al., 2012).

Meat and meat products are important sources of dietary cholesterol and saturated fat. The consumption of meat products naturally increases serum total and LDL (low-density lipoproteins) cholesterol levels (Park et al., 1991; Chizzolini et al., 1999; Wahrburg et al., 2002). However, it should also be noted that some studies conflict with the direct correlation between the consumption of red or processed meat and cardiovascular disease (Wagemakers et al., 2009; McAfee et al., 2010; O'Connor et al., 2017). On the other hand, some research have indicated that red meat may be associated with several cancers, predominantly colorectal cancer, for which high intake of fat is one of the risk factors (Cross \& Sinha, 2004; Di Maso et al., 2013; Oostindjer et al., 2014; Ekmekcioglu et al., 2018).
Lamb, beef, organ (liver, kidney and heart) and sucuk are consumed in very high amounts in the southern, eastern and southeastern Anatolia in Turkey as roasted, fried, barbecued or shish kebab (Gönülalan et al., 2004). Shish kebab refers to a common form of barbequing: Meat to be barbequed is either cut in form of cubes of 3-4 cm size or minced and mixed with spices and cooked on a skewer in a brazier containing charcoal embers. Sucuk, a Turkish style dry-fermented sausage, is another popular meat product in Turkey which contains high amount of dietary cholesterol and lipids (Gökalp et al., 1988; Bozkurt \& Erkmen, 2002; Bozkurt \& Erkmen, 2004). Tail fat is often used in kebabs to add flavor and prevent burn-up. Also, tail fat is added to sucuk to provide characteristic flavor and texture.

There is limited information available on the effect of different cooking procedures, especially barbequing, on the cholesterol and fat levels of meat products. This study aims to answer how much of the fat and cholesterol initially present in a meat product remain after cooking with different procedures. The results of this study are expected to be a reference for dietary fat and cholesterol intake with the consumption of cooked meat products. 


\section{Materials and methods}

\subsection{Sample preparation}

Lamb, beef, tail fat, sucuk of two different brands, and liver were obtained from a local market in Gaziantep, Turkey. One kilogram of each type of meat products was used in the analysis. In order to obtain a homogeneous distribution of cholesterol, moisture, and fat; lamb, beef and tail fat were each minced in a meat grinder (Tefal Prep'Line 1600, France) to about $4 \mathrm{~mm}$ of particle size. Shish kebab of lamb and spicy-lamb were purchased as raw from a retail restaurant in Gaziantep, Turkey. Liver was cut as $2 \times 2 \times 2 \mathrm{~cm}$ cubes, and sucuk as $28 \mathrm{~mm}$-diameter, 3 mm-thick discs.

\subsection{Cooking procedures}

A sample of 200-g of lamb, beef, tail fat or sucuk of each brand, prepared in two batches, was fried at $200 \pm 5^{\circ} \mathrm{C}$ in a pan on an electrical heating device (Velp Scientifica, Italy). Two samples were taken from each batch initially before frying and 3, 6, and 12 minutes after frying, except for tail fat, for which samples were taken before frying and 3, 6, 9 minutes after frying, and when it totally melted. The samples were then analyzed to determine the cholesterol, moisture and fat contents. The same procedure was repeated by adding $40 \mathrm{~mL}$ olive oil to $200 \mathrm{~g}$ sample of beef or sucuk at the same temperature. After frying, the oil and samples were analyzed separately for their cholesterol, moisture and fat contents.

Kebabs of lamb, spicy-lamb, and liver were analyzed for their cholesterol, moisture and fat contents before and after barbequing into shish kebab on a skewer in a brazier containing charcoal embers. Two of each kebab samples were analyzed for their cholesterol, moisture and fat contents before and after barbequing.

During the course of cooking; fat, moisture, and cholesterol were considered to be the migrating components while the carbohydrates, proteins, fibers etc. were treated as non-migrating dry solids.

\subsection{Determination of cholesterol}

Cholesterol content of meat products was determined colorimetrically by the modified Liebermann-Burchard method (Abel et al., 1952; Xiong et al., 2007). The results were expressed as 'mg cholesterol per $100 \mathrm{~g}$ of sample' and 'mg cholesterol per $g$ of non-fat dry solid' on wet and dry bases, respectively.

\section{Preparation of reagent}

The Liebermann-Burchard reagent was prepared as follows: 1.5 volume of concentrated sulphuric acid (Merck, Germany) was mixed with 30 volumes of acetic anhydride (Merck, Germany). The mixture was chilled to $10{ }^{\circ} \mathrm{C}$ and kept in refrigerator for 10 minutes. Following this, 15 volumes of glacial acetic acid (Merck, Germany) were added with stirring to the mixture, which was then allowed to warm up to room temperature. The reagent was prepared freshly for each analysis.
Preparation of standard cholesterol solution for calibration curve

Pure cholesterol (Merck, Germany), $10 \mathrm{mg}$, was dissolved in $50 \mathrm{~mL}$ of ethanol absolute (Merck, Germany). Five $\mathrm{ml}$ of this solution was then transferred into a $25-\mathrm{mL}$ flask followed

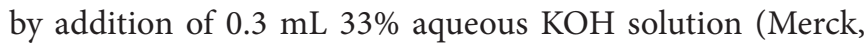
Germany), $10 \mathrm{~mL}$ hexane (Merck, Germany) and $6 \mathrm{~mL}$ water. The flask was shaken for 1 minute. After complete separation; $0.5,1.0,2.0,3.0,4.0$, and $5.0 \mathrm{~mL}$ of the upper hexane layers were transferred into separate test tubes. Finally, the solvent was evaporated by heating the tubes in a hot water bath.

Six $\mathrm{mL}$ of the Liebermann-Burchard reagent was added to each tube. The test tubes were then kept at room temperature for 30 minutes. The absorbance of each solution was measured at $550 \mathrm{~nm}$ against a blank which was prepared without cholesterol by using a spectrophotometer (Novaspec II, Pharmacia Biotech., Cambridge, England). Finally the calibration curve was plotted.

\section{Determination of cholesterol content of samples}

Nine $\mathrm{mL}$ ethanol and $1 \mathrm{~mL} 33 \% \mathrm{KOH}$ solution were added to 1-g homogenized sample and mixed thoroughly for 20 seconds. This was followed by saponification of the non-sterol lipids for which the sample was cooled, $5 \mathrm{~mL}$ deionized water added, and stirred for 2 minutes. After the addition of $10 \mathrm{~mL}$ hexane, the contents were shaken and centrifuged (Hettich, Germany) for 3 minutes at $358 \mathrm{xg}$. The upper layer was separated carefully and transferred to a new flask. After $10 \mathrm{~mL}$ hexane was added to the remaining part, each sample was re-centrifuged for 3 minutes at $358 \mathrm{xg}$. The upper layer was separated and transferred to the corresponding flasks. A 6-mL of Liebermann-Burchard reagent was then added to each sample tube. The tubes were kept at room temperature for 30 minutes after which their absorbance was measured against a blank prepared similarly without the sample.

Like other vegetable oils, olive oil contains some sterols in the range of 180-265 mg per $100 \mathrm{~g}$ of oil depending on the grade of olive oil (Morales \& Przybylski, 2000). In order to eliminate the interference of sterol coming from olive oil involved in the frying experiments, the blank for samples fried with olive oil was prepared as follows: $40 \mathrm{~mL}$ of olive oil was heated at $200 \pm 5^{\circ} \mathrm{C}$ for $12 \mathrm{~min}$, after which $1 \mathrm{~g}$ fried olive oil was taken, and the same procedure was followed with fried olive oil instead of the sample. The cholesterol content of each sample was determined from the calibration curve obtained $\left(\mathrm{R}^{2}=0.9967\right)$.

\subsection{Determination of fat and moisture contents}

Total fat and moisture contents of samples were determined in accordance with Association of Official Analytical Chemists (2000). The fat values were given as ' $\% \mathrm{w} / \mathrm{w}$ ' and ' $\mathrm{g}$ fat per $\mathrm{g}$ of non-fat dry solid' on wet and dry bases, respectively. The moisture values were given as ' $\% \mathrm{w} / \mathrm{w}$ ' and ' $\mathrm{g}$ moisture per $\mathrm{g}$ of non-fat dry solid' on wet and dry bases, respectively.

\subsection{Statistical analysis}

Each analysis was carried out in duplicate. The contents of cholesterol, moisture and fat in samples were compared using ANOVA to determine significant differences $(p<0.05)$. The ANOVA, multiple range analysis (Duncan), and Pearson correlation tests were performed by using SPSS version 9.0 (SPSS Inc., Chicago, IL, USA). 


\section{Results and discussion}

On wet basis, the cholesterol, fat, and moisture contents were all expressed per the total weight of the meat product that consists of the weights of fat, moisture, and non-fat dry solids. Therefore, any change in cholesterol, fat, or moisture was accompanied by a change in total weight. On dry basis, the cholesterol, fat, and moisture contents were expressed per g of non-fat dry solids, so that the total weight of a meat product remained constant as the contents of cholesterol, moisture, and fat changed. The basis of expression is important because it may lead to misunderstanding or confusion among consumers.

\subsection{Frying of lamb}

Cholesterol, fat, and moisture contents of lamb traced during frying periods are given in Figure 1. On wet basis, the cholesterol, fat, and moisture contents of lamb were observed to be $105.60 \pm 4.95 \mathrm{mg} / 100 \mathrm{~g}$ of lamb, $10.53 \pm 1.21 \%$, and $70.31 \pm 3.43 \%$ before frying, respectively, and $131.90 \pm 2.80 \mathrm{mg} / 100 \mathrm{~g}$ of lamb, $12.53 \pm 0.98 \%$, and $9.52 \pm 1.54 \%$ after frying for $12 \mathrm{~min}$, respectively. One-way ANOVA and multiple range tests indicated that the cholesterol and fat contents gradually increased $(p<0.05)$, while the moisture content decreased $(p<0.05)$ during frying. This pattern was expected because percent solids in lamb increased during frying due to the evaporation of water. The Pearson correlation test demonstrated that, on wet basis, a significant relation $(\mathrm{p}<0.05)$ exists for cholesterol-moisture and cholesterol-fat contents of lamb with Pearson correlation coefficients of -0.851 and 0.829 , respectively. The negative correlation means that the decrease in the moisture content was accompanied by an increase in the cholesterol content. However, cholesterol and fat contents increased simultaneously during frying. The increment in fat level is attributed to the higher percent removal of water than that of fat during frying.

On dry basis, the cholesterol content of lamb decreased $(\mathrm{p}<0.05)$ from $5.511 \pm 0.259$ to $1.692 \pm 0.036 \mathrm{mg}$ cholesterol per g non-fat dry solid during $12 \mathrm{~min}$-frying process (Figure 1). Similarly, fat content decreased $(p<0.05)$ from $0.550 \pm 0.064$ to $0.161 \pm 0.013 g$ per g non-fat dry solid. This might be due to the diffusion of fat which carried away some of the cholesterol. Another reason for the cholesterol loss might be partial oxidization during frying (Conchillo et al., 2004). Also, moisture content decreased ( $\mathrm{p}<0.05$ ) from $3.670 \pm 0.179$ to $0.122 \pm 0.020 \mathrm{~g}$ per g non-fat dry solid. On dry basis ( $\mathrm{mg}$ or g migrating component per g non-fat dry solid), cholesterol-moisture (0.999), cholesterol-fat (0.992), and moisture-fat (0.988) correlations were found to be significant $(p<0.05)$. It could be concluded that, on dry basis, cholesterol, moisture and fat contents decreased during frying, and all the factors were affected $(p<0.05)$ from each other.

\subsection{Frying of tail fat}

The cholesterol, fat, and moisture contents of tail fat during frying are given in Figure 2. On wet basis, the initial cholesterol content was found to be $43.30 \pm 8.78 \mathrm{mg} / 100 \mathrm{~g}$ of tail fat, which
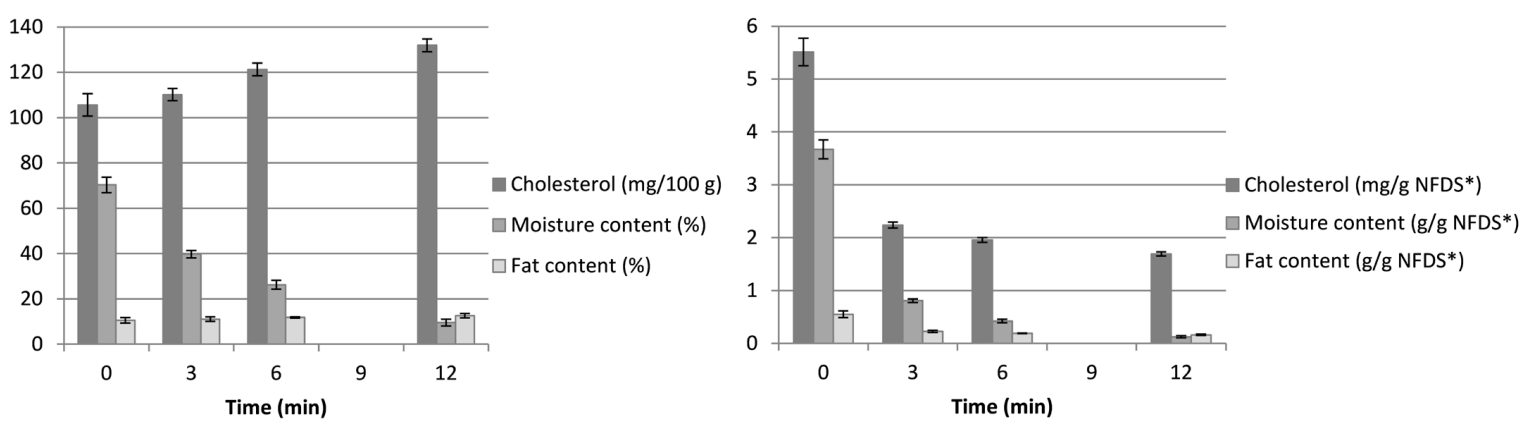

Figure 1. Cholesterol, moisture, and fat contents of lamp during frying; on wet basis (on the left) and on dry basis (on the right). ${ }^{\star}$ FDS: non-fat dry solids.
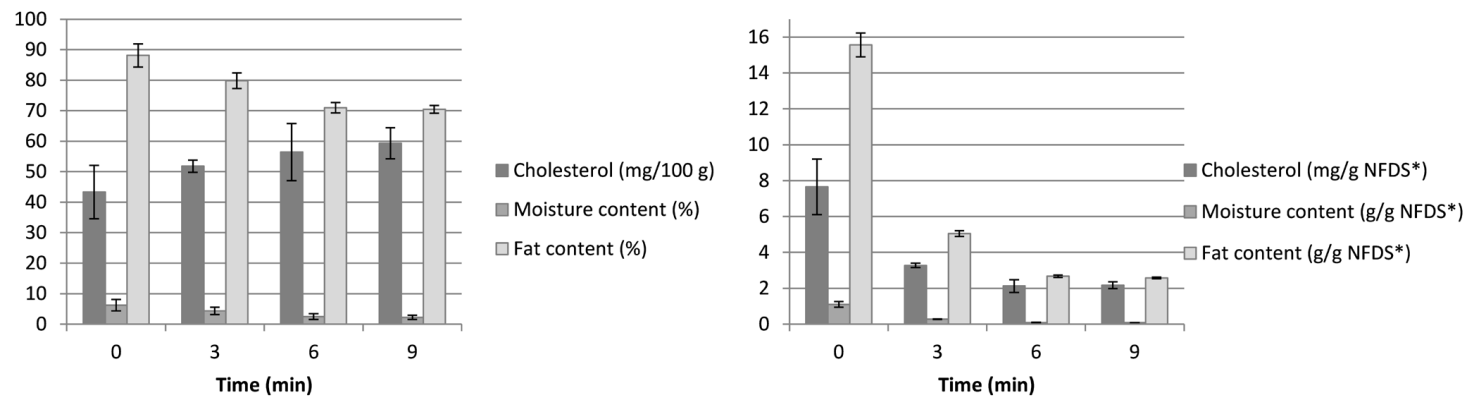

Figure 2. Cholesterol, moisture, and fat contents of tail fat during frying; on wet basis (on the left) and on dry basis (on the right). ${ }^{\star}$ NFDS: non-fat dry solids. 
increased to $59.30 \pm 5.10 \mathrm{mg} / 100 \mathrm{~g}$ after $9 \mathrm{~min}$ of frying at $200^{\circ} \mathrm{C}$, yet not significantly $(\mathrm{p}>0.05)$. After complete melting, the cholesterol content was determined as $69.05 \mathrm{mg} / 100 \mathrm{~g}$ of tail fat. The initial fat and moisture contents of tail fat were $88.10 \pm 3.77 \%$ and $6.24 \pm 1.87 \%$, which decreased to $70.46 \pm 1.26$ and $2.21 \pm 0.65 \%$ after 9 min of frying, respectively. During frying, the fat and moisture contents decreased significantly $(\mathrm{p}<0.05)$ due to the melting of fat and evaporation of water, respectively. The Pearson correlation test indicated that only moisture-fat relationship exists on wet basis with a positive Pearson coefficient of 0.994 .

On dry basis, the cholesterol content decreased significantly $(\mathrm{p}<0.05)$ from $7.650 \pm 1.551$ to $2.169 \pm 0.187 \mathrm{mg}$ cholesterol per $\mathrm{g}$ non-fat dry solid during frying (Figure 2). Similarly, the fat content decreased $(\mathrm{p}<0.05)$ from $15.565 \pm 0.666$ to $2.578 \pm 0.046 \mathrm{~g}$ per $g$ non-fat dry solid, and the moisture content decreased $(\mathrm{p}<0.05)$ from $1.102 \pm 0.154$ to $0.081 \pm 0.013 \mathrm{~g}$ per $\mathrm{g}$ non-fat dry solid. The Pearson correlation coefficients were found to be 0.987, 0.961, and 0.993 for cholesterol-moisture, cholesterol-fat, and moisture-fat correlations, respectively. These results indicate that all parameters on dry basis were affected $(\mathrm{p}<0.05)$ from each other.

\subsection{Frying of beef}

The cholesterol, fat, and moisture contents of beef fried with and without olive oil are given in Figure 3.

\section{Frying without olive oil}

On wet basis, the cholesterol content of beef samples was found to be $126.86 \pm 4.98 \mathrm{mg} / 100 \mathrm{~g}$ before frying, and increased $(\mathrm{p}<0.05)$ to $167.79 \pm 4.98 \mathrm{mg} / 100 \mathrm{~g}$ of beef after $12 \mathrm{~min}$ of frying without olive oil. While the fat content increased $(\mathrm{p}>0.05)$ from $9.66 \pm 0.69$ to $12.41 \pm 0.12 \%$, the moisture content decreased $(\mathrm{p}<0.05)$ from $70.42 \pm 4.29$ to $9.58 \pm 0.95 \%$. The increment in cholesterol and fat contents could be due to the decreasing moisture content of beef samples during frying.

On dry basis, the cholesterol content of beef was found to decrease significantly $(\mathrm{p}<0.05)$ from $6.368 \pm 0.250$ to $2.151 \pm 0.064 \mathrm{mg}$ cholesterol per g non-fat dry solid during frying (Figure 3 ). On the other hand, the fat content decreased $(\mathrm{p}<0.05)$ from $0.485 \pm 0.035$ to $0.159 \pm 0.002 \mathrm{~g}$ per g non-fat dry solid, and moisture content $(\mathrm{p}<0.05)$ from $3.535 \pm 0.216$ to $0.123 \pm 0.012 \mathrm{~g}$ per g non-fat dry solid, respectively. The Pearson correlation test indicated that a relation $(\mathrm{p}<0.05)$ exists between the cholesterol and fat contents of beef on wet basis, and between moisture and fat contents on dry basis.

The cholesterol content of beef was reported in the literature as $52-55 \mathrm{mg} / 100 \mathrm{~g}$ by Piironen et al. (2002) and $60 \mathrm{mg} / 100 \mathrm{~g}$ by Chizzolini et al. (1999). Rhee et al. (1982) observed that cholesterol content of beef steaks increased from about $65 \mathrm{mg} / 100 \mathrm{~g}$ to $87 \mathrm{mg} / 100 \mathrm{~g}$. However, their values on dry basis decreased after cooking at $75{ }^{\circ} \mathrm{C}$. They deduced that the total cholesterol level in beef steaks did not increase due to cooking, yet decreased by the amount included in cooking drip as it was in our study. The variation in the cholesterol level has been attributed to some factors such as species, breed, sex, muscle, and feeding regime. Roseland et al. (2018) compared the cooked cuts of chuck eye, ribeye, tenderloin, shoulder and top loin obtained from beef carcasses for nutrient differences. Total fat and cholesterol levels ranged from 6.9 to $24.2 \mathrm{~g}$ and 80 to $98 \mathrm{mg}$ (per $100 \mathrm{~g}$ ), respectively. Concentrations of cholesterol and fatty acids were found to be mostly similar between roasted and grilled paired cuts.

\section{Frying with olive oil}

Beef was also fried in the presence of olive oil to evaluate its effect on the removal of cholesterol. The results are given in Figure 3. After 12-min frying in olive oil, the cholesterol content of beef was found to be $159.53 \pm 8.92 \mathrm{mg} / 100 \mathrm{~g}$. The cholesterol content of beef showed an increase $(\mathrm{p}<0.05)$ on wet basis and a decrease on dry basis $(\mathrm{p}<0.05)$ after frying with or without olive oil. Duncan's multiple range test indicated the lowest cholesterol content was found in oil after beef was fried with olive oil. The cholesterol content in meat part after frying with and without olive oil were not statistically different ( $p>0.05)$. It could then be concluded that the presence of olive oil did not have a significant effect on the cholesterol content of beef during frying.

The fat and moisture contents of beef after frying with olive oil were about $23.13 \pm 0.26 \%$ and $9.46 \pm 1.32 \%$, respectively. During frying, the fat content increased $(\mathrm{p}<0.05)$ on wet basis, yet decreased $(p<0.05)$ on dry basis. The fat content of beef fried with olive oil was naturally found to be higher $(p<0.05)$ than that of the beef fried without olive oil. On the other hand, the moisture content of beef fried with or without olive oil was
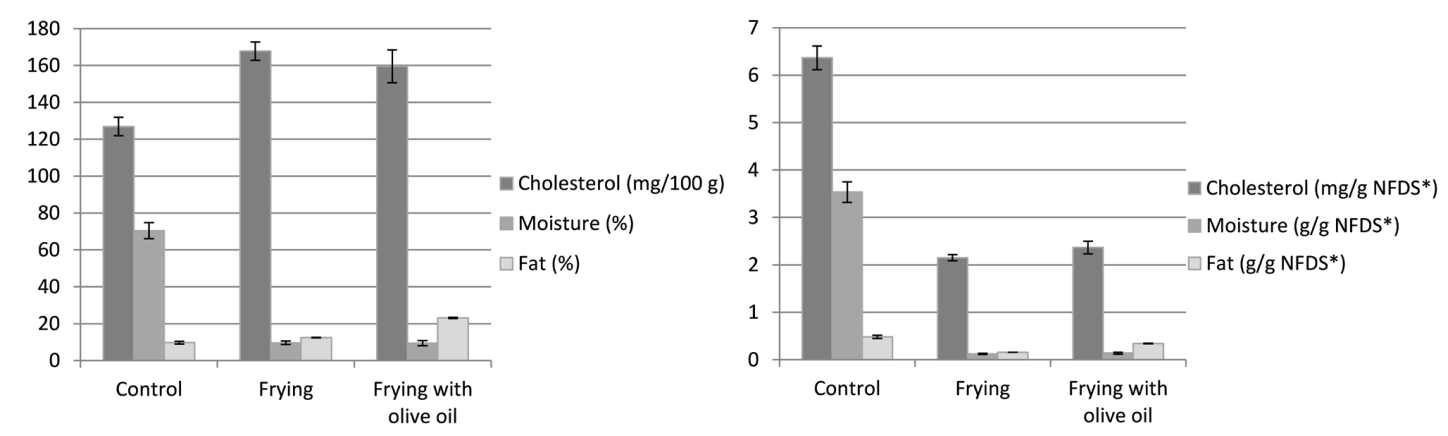

Figure 3. Cholesterol, moisture, and fat contents of beef fried; on wet basis (on the left) and on dry basis (on the right). ${ }^{\star}$ NFDS: non-fat dry solids. 
not found to be significantly different $(p>0.05)$. Frying process significantly $(\mathrm{p}<0.05)$ reduced the moisture content on wet or dry basis, which could be due to the removal of water as evaporation or drip loss as a result of heat application. These results were in agreement with Scheeder et al. (2001).

In the case of beef fried with olive oil, all the parameters were affected by each other on dry basis. However, Piironen et al. (2002) did not observe such a relation between the cholesterol and fat contents of beef cuts, which might be attributed to the sample size. In the present study, beef was minced to about $4 \mathrm{~mm}$ while Piironen et al. (2002) used beef cuts as samples. The drip loss of fat in minced beef would, therefore, be easier than that of beef cuts.

\subsection{Shish-kebabs (lamb, hot-spicy lamb, and liver)}

The cholesterol, fat, and moisture contents in kebabs of lamb, hot-spicy lamb, and liver were determined before and after cooking the meat on charcoal embers (as shish kebab). The results are given in Figure 4 and Figure 5 on wet and dry bases, respectively. The cholesterol content of lamb kebab was about $166.64 \pm 17.04 \mathrm{mg} / 100 \mathrm{~g}$, which decreased $(\mathrm{p}>0.05)$ to $160.04 \pm 13.42 \mathrm{mg} / 100 \mathrm{~g}$ after cooking (Figure 4 ). This was probably due to melting and dripping of fat during cooking as observed visually. At the same time, some of the cholesterol dissolved in fat may also have been lost. Similar trends were observed for spicy-lamb kebab, in which the cholesterol content decreased but not significantly ( $\mathrm{p}>0.05)$. The spicy-lamb kebab, however, had higher initial cholesterol content $(183.64 \pm 13.20 \mathrm{mg} / 100 \mathrm{~g})$ than that of lamb kebab, which is due to the higher initial fat and thus cholesterol content of spicy-lamb kebab. The initial cholesterol content of liver kebab was about $287.82 \pm 12.48 \mathrm{mg} / 100 \mathrm{~g}$ and increased $(\mathrm{p}<0.05)$ to about $439.92 \pm 21.64 \mathrm{mg} / 100 \mathrm{~g}$ on wet basis during the cooking period.

Mustafa (1988) observed that during cooking of liver the cholesterol content increased from $191.65 \mathrm{mg} / 100 \mathrm{~g}$ to $385.12 \mathrm{mg} / 100 \mathrm{~g}$. These are somewhat in agreement with our results. However, on dry basis, the cholesterol level of liver kebab decreased $(\mathrm{p}<0.05)$ from $14.859 \pm 0.644$ to $9.746 \pm 0.480 \mathrm{mg}$ cholesterol per $g$ non-fat dry solid as expected because of the fat and thus the cholesterol loss due to dripping (Figure 5). In the case of shish-kebab cooking, the fat was lost continuously from the meat as there was no dish to retain or collect it.

The initial fat and moisture contents of kebabs were found to be $26.14 \pm 1.91 \%$ and $56.84 \pm 3.24 \%$ for lamb kebab; $29.66 \pm 1.43 \%$ and $59.32 \pm 3.79 \%$ for hot-spicy lamp kebab; and $8.98 \pm 0.97$ and $71.65 \pm 3.65 \%$ for liver kebab, on wet basis, respectively (Figure 4 ). The fat content of kebabs did not change significantly ( $p>0.05)$ on wet basis after barbequing, while the moisture content decreased significantly $(\mathrm{p}<0.05)$. However, the cholesterol, fat, and moisture contents of all kebabs showed a decrease $(\mathrm{p}<0.05)$ on dry basis. The Pearson correlation test indicated that no relationship $(\mathrm{p}>0.05)$ existed between the cholesterol, moisture and fat contents of kebabs on wet basis. However, all the parameters were found to be affected $(\mathrm{p}<0.05)$ from each other on dry basis.

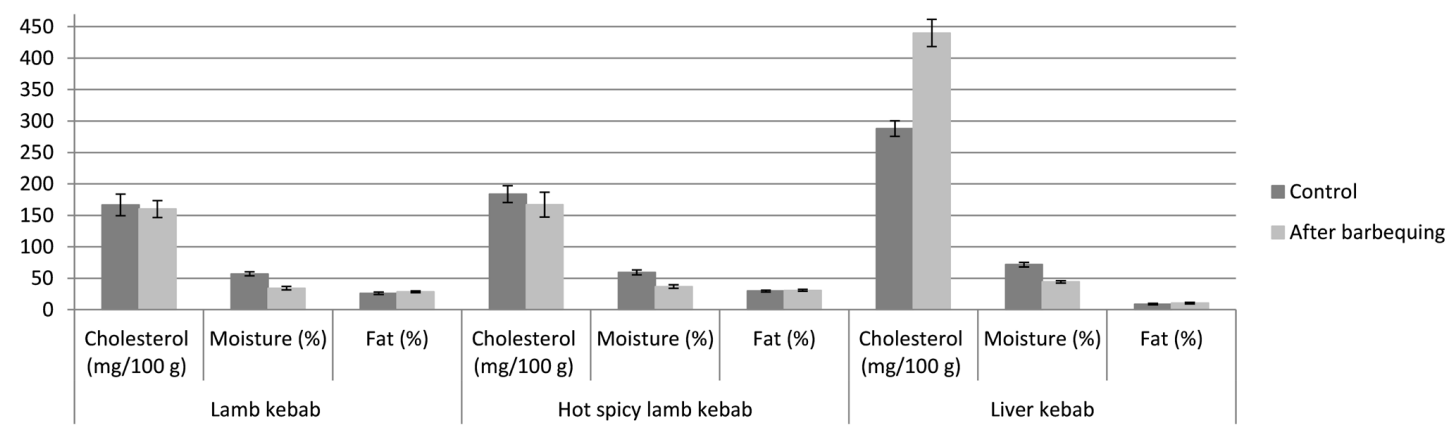

Figure 4. Cholesterol, moisture, and fat contents (on wet basis) of kebabs barbequed.

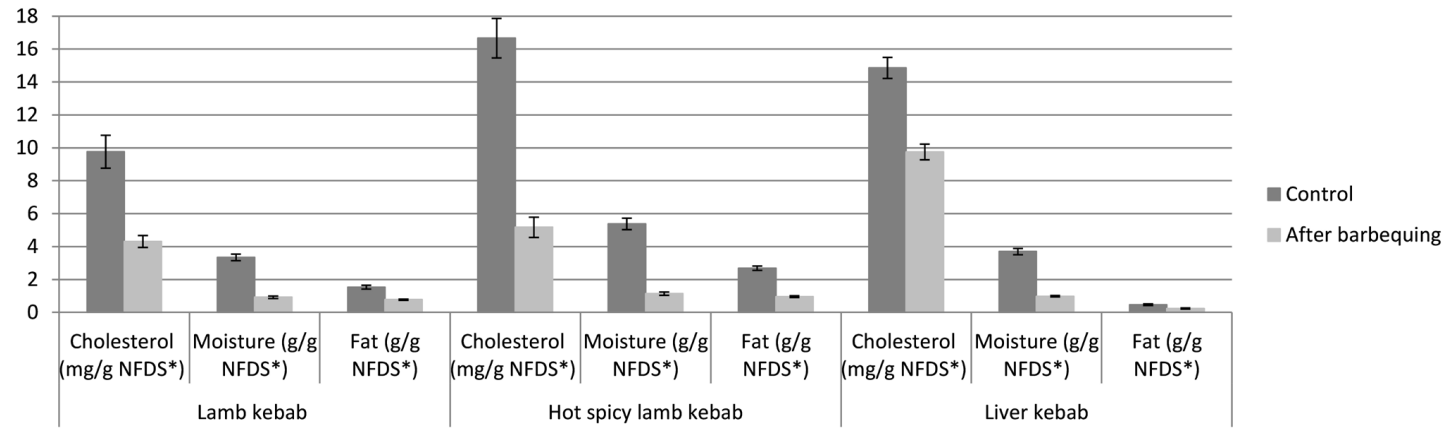

Figure 5. Cholesterol, moisture, and fat contents (on dry basis) of kebabs barbequed. ${ }^{\star}$ NFDS: non-fat dry solids. 


\subsection{Frying of sucuk}

The cholesterol, fat, and moisture contents of sucuks of two different brands, denoted as Sucuk-1 and Sucuk-2, were investigated before and after frying at $200^{\circ} \mathrm{C}$ with or without olive oil. The results on wet and dry bases are given in Figure 6 and Figure 7, respectively.

\section{Frying without olive oil}

The cholesterol content of Sucuk- 1 and Sucuk- 2 were found to be $139.10 \pm 1.30$ and $180.57 \pm 17.13 \mathrm{mg} / 100 \mathrm{~g}$ on wet basis before frying. The difference between the cholesterol contents of sucuks could be due to the differences in the ingredients. For instance, Sucuk-2 may have contained some offal. The cholesterol contents in meat part of Sucuk-1 and Sucuk-2 decreased ( $\mathrm{p}<0.05$ ) to $91.83 \pm 1.85$ and $129.49 \pm 5.66 \mathrm{mg} / 100 \mathrm{~g}$ of sucuk, respectively, after frying without olive oil (Figure 6). The reduction of cholesterol content could be due to the cholesterol which was carried away within melted fat during the diffusion of oil from sucuk that was being fried. In oil part, the cholesterol contents of Sucuk-1 and Sucuk-2 were found to be $87.53 \pm 1.45$ and $193.96 \pm 1.46 \mathrm{mg} / 100 \mathrm{~g}$ of oil, respectively.

On dry basis, the cholesterol content of Sucuk-1 decreased $(\mathrm{p}<0.05)$ from $6.431 \pm 0.060$ to $1.755 \pm 0.036 \mathrm{mg}$ cholesterol per g non-fat dry solid during the frying process as a result of moisture loss (Figure 7). Similarly, the cholesterol content of Sucuk-2 decreased $(\mathrm{p}<0.05)$ from $9.236 \pm 0.877$ to $2.633 \pm 0.115 \mathrm{mg}$ cholesterol per g non-fat dry solid. These results were in agreement with the findings of Rodriguez-Estrada et al. (1997), who found that during the cooking of hamburger the cholesterol content decreased both on wet and dry bases.

The initial fat contents of Sucuk- 1 and Sucuk-2 were found to be about $33.74 \pm 1.54 \%$ and $38.29 \pm 1.49 \%$, respectively, on wet basis, which decreased ( $p>0.05$ ) to $30.02 \pm 0.26 \%$ and $32.53 \pm 0.98 \%$, respectively, after frying without olive oil due to the melting of fat during frying. The initial moisture contents of Sucuk- 1 and Sucuk- 2 were found to be about $44.63 \pm 1.44 \%$ and $42.16 \pm 1.87 \%$, respectively, which decreased $(\mathrm{p}<0.05)$ to about $17.65 \pm 0.65 \%$ and $18.29 \pm 0.42 \%$ after frying. Likewise, the fat and moisture contents of Sucuk-1 and Sucuk-2 on dry basis decreased significantly $(\mathrm{p}<0.05)$ after frying. Similar results were observed in case of cooking of hamburger (Rodriguez-Estrada et al., 1997), in which the moisture and fat losses were about $17.5 \%$ and $16 \%$, respectively, during different cooking procedures.

\section{Frying with olive oil}

After frying with olive oil, the cholesterol contents in meat part of Sucuk-1 and Sucuk-2 decreased to about $110.80 \pm 0.84$ and $131.54 \pm 0.75 \mathrm{mg} / 100 \mathrm{~g}$ on wet basis $(\mathrm{p}<0.05)$ (Figure 6), and to $2.288 \pm 0.018$ and $2.834 \pm 0.016 \mathrm{mg}$ cholesterol per g non-fat dry solid $(\mathrm{p}<0.05)$, respectively (Figure 7 ). The cholesterol contents in oil part were found to be $81.85 \pm 8.09$ and $204.98 \pm 9.48 \mathrm{mg} / 100 \mathrm{~g}$ for Sucuk-1 and Sucuk-2, respectively. Similarly, the fat contents of Sucuk-1 and

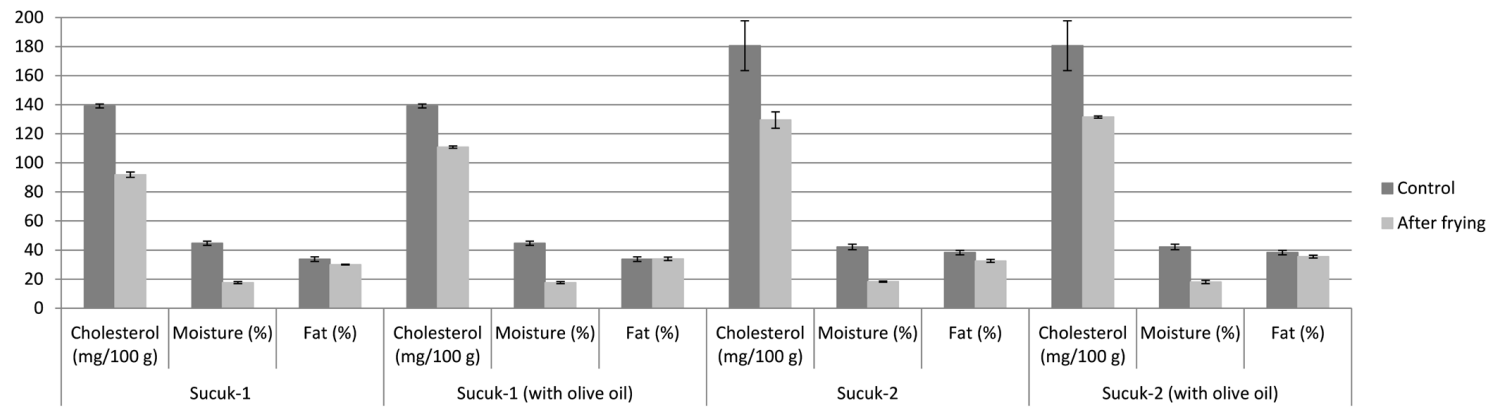

Figure 6. Cholesterol, moisture, and fat contents (on wet basis) of sucuks fried.

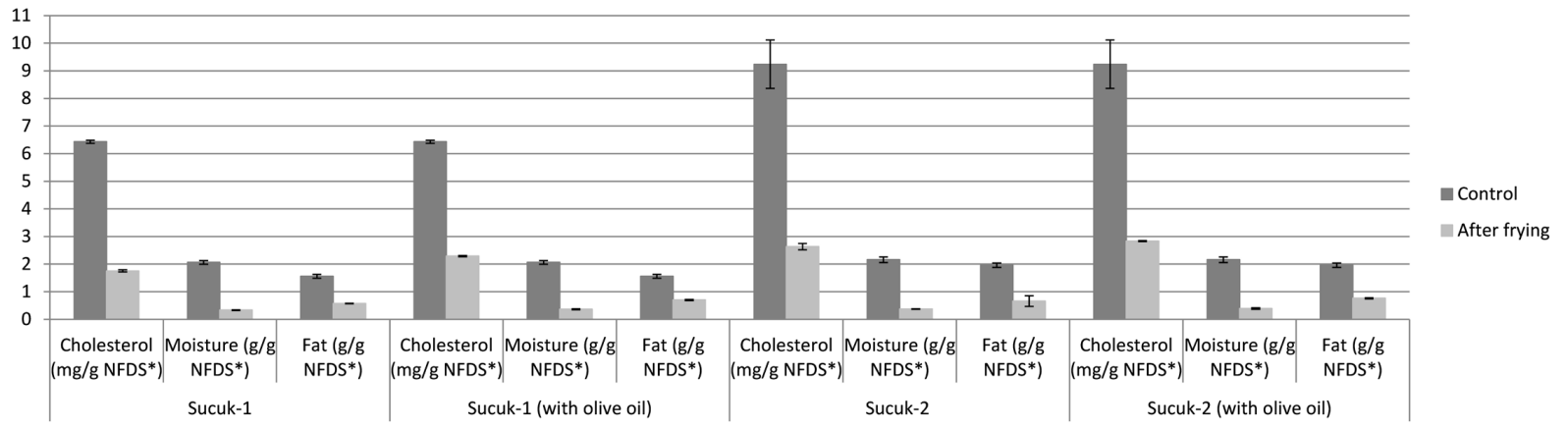

Figure 7. Cholesterol, moisture, and fat contents (on dry basis) of sucuks fried. ${ }^{\star N F D S: ~ n o n-f a t ~ d r y ~ s o l i d s . ~}$ 
Sucuk-2 decreased to $33.96 \pm 1.21$ and $35.49 \pm 0.98 \%$ on wet basis ( $p>0.05$ ), and to $0.701 \pm 0.025$ and $0.765 \pm 0.022 \mathrm{~g}$ fat per $\mathrm{g}$ non-fat dry solid $(\mathrm{p}<0.05)$, respectively. The moisture contents of sucuks decreased significantly $(\mathrm{p}<0.05)$ on both wet and dry bases. Also, there were statistical differences $(\mathrm{p}<0.05)$ between the moisture contents of sucuks fried with or without olive oil.

Pearson correlation test indicated that the cholesterol and moisture contents of Sucuk-1 fried with or without olive oil were related $(\mathrm{p}<0.05)$. However, there was no relationship observed between the cholesterol and moisture contents of Sucuk- 2 fried with or without olive oil on wet basis. Also, the cholesterol content of Sucuk-2 was affected by the fat content when fried without olive oil on wet basis. However, all the parameters were affected $(p<0.05)$ by each other on dry basis for sucuks of both brands.

Piironen et al. (2002) found that the cholesterol content of sausages ranged between 36 to $75 \mathrm{mg} / 100 \mathrm{~g}$, and the highest cholesterol content was observed in Salami type sausage, which contains high amount of fat and dry solid. Similarly, Chizzolini et al. (1999) reported that the cholesterol content of sausages would be in the range of $40-100 \mathrm{mg} / 100 \mathrm{~g}$. Also, Würstel type sausage that contains $32 \%$ fat had the highest cholesterol content. Our results were correlated with these findings indicating that the higher fat the sausage contains, the higher its cholesterol content would be.

\section{Conclusion}

The cooking procedure and the type of the meat product affected in different ways how the cholesterol and fat contents of meat products changed during cooking. Regardless of the meat product or cooking procedure, the moisture content on wet or dry basis exhibited a significant decrease $(p<0.05)$ after cooking, as expected. Normally, one expects the cholesterol of a kebab to decrease due to drip loss during barbequing. However, the cholesterol content of liver kebab, as an example, showed an increase $(\mathrm{p}<0.05)$ on wet basis, while showed a decrease $(\mathrm{p}<0.05)$ on dry basis. Therefore, the consumers should be aware of the difference between the expressions on wet and dry bases.

This study also indicates that frying with olive oil does not appear to affect the cholesterol and fat contents of selected meat products significantly. In conclusion, not only the amount of dietary cholesterol and its interaction with the other constituents of a cooked meat product, but also the behavior of the cholesterol in human body need to be further investigated to establish a reliable limit of cholesterol intake from cooked meat products.

\section{References}

Abel, L. L., Levy, B. B., Brodie, B. B., \& Kendall, F. E. (1952). A simplified method for the estimation of total cholesterol in serum and demonstration of its specificity. The Journal of Biological Chemistry, 195(1), 357-366. PMid:14938387.

Association of Official Analytical Chemists - AOAC. (2000). Official methods of analysis (17th ed.). Gaithersburg: AOAC.

Bozkurt, H., \& Erkmen, O. (2002). Effect of starter cultures and additives on the quality of Turkish style sausage (sucuk). Meat Science, 61(2), 149-156.

Bozkurt, H., \& Erkmen, O. (2004). Effect of temperature, humidity and additives on the formation of biogenic amines in sucuk during ripening and storage periods. Food Science \& Technology International, 10(1), 21-28. http://dx.doi.org/10.1177/1082013204041992.

Chizzolini, R., Zanardi, E., Dorigoni, V., \& Ghidini, S. (1999). Calorific value and cholesterol content of normal and low-fat meat and meat products. Trends in Food Science \& Technology, 10(4-5), 119-128. http://dx.doi.org/10.1016/S0924-2244(99)00034-5.

Conchillo, A., Ansorena, D., \& Astiasaran, I. (2004). The effect of cooking and storage on the fatty acid profile of chicken breast. European Journal of Lipid Science and Technology, 106(5), 301-306. http://dx.doi.org/10.1002/ejlt.200300908.

Cross, A. J., \& Sinha, R. (2004). Meat-related mutagens/carcinogens in the etiology of colorectal cancer. Environmental and Molecular Mutagenesis, 44(1), 44-55. http://dx.doi.org/10.1002/em.20030. PMid:15199546.

Di Maso, M., Talamini, R., Bosetti, C., Montella, M., Zucchetto, A., Libra, M., Negri, E., Levi, F., La Vecchia, C., Franceschi, S., Serraino, D., \& Polesel, J. (2013). Red meat and cancer risk in a network of case-control studies focusing on cooking practices. Annals of Oncology : Official Journal of the European Society for Medical Oncology, 24(12), 3107-3112. http://dx.doi.org/10.1093/annonc/ mdt392. PMid:24121119.

Ekmekcioglu, C., Wallner, P., Kundi, M., Weisz, U., Haas, W., \& Hutter, H. P. (2018). Red meat, diseases and healthy alternatives: a critical review. Critical Reviews in Food Science and Nutrition, 58(2), 247-261. http://dx.doi.org/10.1080/10408398.2016.1158148. PMid:27128451.

Gökalp, H. Y., Yetim, H., Kaya, M., \& Ockerman, H. W. (1988). Saprophytic and pathogenic bacteria levels in Turkish Soudjucks manufactured in Erzurum, Turkey. Journal of Food Protection, 51(2), 121-125. http://dx.doi.org/10.4315/0362-028X-51.2.121.

Gönülalan, Z., Yetim, H., \& Kose, A. (2004). Quality characteristics of doner kebab made from sucuk dough which is a dry fermented Turkish sausage. Meat Science, 67(4), 669-674. http://dx.doi.org/10.1016/j. meatsci.2004.01.009. PMid:22061816.

Johnston, T. P., Korolenko, T. A., Pirro, M., \& Sahebkar, A. (2017). Preventing cardiovascular heart disease: promising nutraceutical and non-nutraceutical treatments for cholesterol management. Pharmacological Research, 120, 219-225. http://dx.doi.org/10.1016/j. phrs.2017.04.008. PMid:28408313.

Kanter, M. M., Kris-Etherton, P. M., Fernandez, M. L., Vickers, K. C., \& Katz, D. L. (2012). Exploring the factors that affect blood cholesterol and heart disease risk: is dietary cholesterol as bad for you as history leads us to believe? Advances in Nutrition, 3(5), 711-717. http:// dx.doi.org/10.3945/an.111.001321. PMid:22983850.

McAfee, A. J., McSorley, E. M., Cuskelly, G. J., Moss, B. W., Wallace, J. M. W., Bonham, M. P., \& Fearon, A. M. (2010). Red meat consumption: an overview of the risks and benefits. Meat Science, 84(1), 1-13. http://dx.doi.org/10.1016/j.meatsci.2009.08.029. PMid:20374748.

Morales, M. T. \& Przybylski, R. (2000). Olive oil oxidation. In J. Harwood \& R. Aparicio (Eds.), Handbook of olive oil: analysis and properties (pp. 472). New York: Springer Science+Business Media. http://dx.doi.org/10.1007/978-1-4757-5371-4_13.

Mustafa, F. A. (1988). Moisture, fat and cholesterol content of some raw, barbecued and cooked organ meats of beef and mutton. Journal of Food Science, 53(1), 270-271. http://dx.doi.org/10.1111/j.1365-2621.1988. tb10225.x.

O’Connor, L. E., Kim, J. E., \& Campbell, W. W. (2017). Total red meat intake of $\geq 0.5$ servings/d does not negatively influence cardiovascular disease risk factors: a systemically searched meta-analysis of randomized controlled trials. The American Journal of Clinical Nutrition, 105(1), 57-69. http://dx.doi.org/10.3945/ajcn.116.142521. PMid:27881394. 
Oostindjer, M., Alexander, J., Amdam, G. V., Andersen, G., Bryan, N. S., Chen, D., Corpet, D. E., De Smet, S., Dragsted, L. O., Haug, A., Karlsson, A. H., Kleter, G., de Kok, T. M., Kulseng, B., Milkowski, A. L., Martin, R. J., Pajari, A. M., Paulsen, J. E., Pickova, J., Rudi, K., Sødring, M., Weed, D. L., \& Egelandsdal, B. (2014). The role of red and processed meat in colorectal cancer development: a perspective. Meat Science, 97(4), 583-596. http://dx.doi.org/10.1016/j. meatsci.2014.02.011. PMid:24769880.

Park, Y. W., Kouassi, M. A., \& Chin, K. B. (1991). Moisture, total fat and cholesterol in goat organ and muscle meat. Journal of Food Science, 56(5), 1191-1193. http://dx.doi.org/10.1111/j.1365-2621.1991. tb04731.x.

Piironen, V., Toivo, J., \& Lampi, A. M. (2002). New data for cholesterol content in meat, fish, milki eggs and their products consumed in Finland. Journal of Food Composition and Analysis, 15(6), 705-713. http://dx.doi.org/10.1006/jfca.2002.1095.

Rhee, K. S., Dutson, T. R., Smith, G. R., Hostetler, R. L., \& Reiser, R. (1982). Cholesterol content of raw and cooked beef longissimus muscles with different degrees of marbling. Journal of Food Science, 47(3), 716-719. http://dx.doi.org/10.1111/j.1365-2621.1982.tb12698.x.

Rodriguez-Estrada, M. T., Penazzi, G., Caboni, M. F., Bertacco, G., \& Lercker, G. (1997). Effect of different cooking methods on some lipid and protein components of hamburger. Meat Science, 45(3), 365-375. http://dx.doi.org/10.1016/S0309-1740(96)00123-4. PMid:22061474.

Roseland, J. M., Nguyen, Q. V., Douglass, L. W., Patterson, K. Y., Howe, J. C., Williams, J. R., Thompson, L. D., Brooks, J. C., Woerner, D. R.,
Engle, T. E., Savell, J. W., Gehring, K. B., Cifelli, A. M., \& McNeill, S. H. (2018). Fatty acid, cholesterol, vitamin, and mineral content of cooked beef cuts from a national study. Journal of Food Composition and Analysis, 66, 55-64. http://dx.doi.org/10.1016/j.jfca.2017.12.003.

Scheeder, M. R. L., Casutt, M. M., Roulin, M., Escher, F., Dufey, P. A., \& Kreuzer, M. (2001). Fatty acid composition, cooking loss and texture of beef patients from meat of bulls fed different fats. Meat Science, 58(3), 321-328. http://dx.doi.org/10.1016/S0309-1740(01)00037-7. PMid:22062263.

Wagemakers, J. J. M. F., Prynne, C. J., Stephen, A. M., \& Wadsworth, M. E. J. (2009). Consumption of red or processed meat does not predict risk factors for coronary heart disease; results from a cohort of British adults in 1989 and 1999. European Journal of Clinical Nutrition, 63(3), 303-311.http://dx.doi.org/10.1038/sj.ejcn.1602954. PMid:18000518.

Wahrburg, U., Kratz, M., \& Cullen, P. (2002). Mediterranean diet, olive oil and health. European Journal of Lipid Science and Technology, 104(9-10), 698-705. http://dx.doi.org/10.1002/14389312(200210)104:9/10<698::AID-EJLT698>3.0.CO;2-A.

Willett, W. C. (1994). Diet and health: what should we eat? Science, 264(5158), 532-537. http://dx.doi.org/10.1126/science.8160011 PMid:8160011.

Xiong, Q., Wilson, W. K., \& Pang, J. (2007). The Liebermann-Burchard reaction: sulfonation, desaturation, and rearrangment of cholesterol in acid. Lipids, 42(1), 87-96. http://dx.doi.org/10.1007/s11745-0063013-5 PMid:17393214. 